\title{
Pretreatment methods as a means of boosting methane production from sewage sludge and its mixtures with grease trap sludge
}

\author{
Anna Grosser ${ }^{1, *}$, and Ewa Neczaj ${ }^{1}$ \\ ${ }^{1}$ Czestochowa University of Technology, Institute of Environmental Engineering, \\ ul. Brzeznicka 60 A, Czestochowa, Poland
}

\begin{abstract}
The main objective of this study was to determine the applicability of the selected pretreatment methods as a means of intensification of methane production from sewage sludge as well as its mixtures with grease trap sludge. The addition of the fat rich material to the digester treating sewage sludge resulted in an increased methane yield as well as volatile solids (VS) removal of up to $36 \%$ (from $134.75 \mathrm{~mL} / \mathrm{g}$ VS to $182.84 \mathrm{~mL} / \mathrm{g}$ VS). Furthermore, thermochemical pretreatment of the co-digestion mixture resulted in an approximately $76 \%$ higher methane yield as compared to the untreated sewage sludge. The energy balance showed that, for both materials ultrasonic pretreatment and thermochemical pretreatment has an energy self-sufficiency. All of the tested models fit the experimental data with coefficients of determination higher than 0.96 .
\end{abstract}

\section{Introduction}

Energy recovery from sewage sludge provides an opportunity not only for sustainable management of this waste, but it is also an interesting option from the energy production standpoint [1]. Biogas which is one of the renewable energy carriers can be used as a substitute for fossil fuels in electricity production or as a fuel for combustion vehicles [2]. Rising fossil fuel prices and the growing interest in renewable energy sources, justifies the attempts of intensifying biogas production from sewage sludge [3,4]. Disadvantages of anaerobic digestion of sewage sludge such as long retention time of sludge in the digester or a low degree of volatile solids (VS) removal are an additional reason for the seeking of new solutions for enhancing the efficiency of this process [3, 5]. From the available intensification options for anaerobic digestion of sewage sludge, two seem particularly interesting, namely co-digestion with other organic wastes with high energy potential (e.g. fatty wastes) and pretreatment of the feedstock prior to its introduction to the digester, methods combining both of the mentioned should also be taken into consideration $[6,7]$. Benefits as well as drawbacks of the techniques mentioned above are well documented in literature $[3,4,6,8,9]$. However, the overwhelming part of these publications relates to sewage sludge. Nevertheless, in the context of the co-digestion process, pretreatment of

*Corresponding author: agrosser@is.pcz.czest.pl 
feedstock also seems to be an interesting approach. However, the available data is still limited due to the fact that pretreatment methods employed for co-digestion have become more widely described in literature only starting from the year 2011. Therefore, more research needs to be carried out, for example in order to assess how pretreatment affects the process performance. For these reasons, the objective of this study was to determine the applicability of the selected pretreatment methods as a means of intensification of methane production from sewage sludge as well as its mixtures with grease trap sludge. Fat rich material was selected due to its high energy potential. As literature data show, theoretically, about $1.425 \mathrm{~L}$ of biogas can be produced from $1 \mathrm{~g}$ of VS lipids, while only $0.830 \mathrm{~L}$, $0.921 \mathrm{~L}$ can be produced respectively from $1 \mathrm{~g}$ of VS carbohydrates and protein [10]. In the context of the legal requirements related to them, such as veterinary regulations i.e. the European Commission Regulation (EC) 1069/2009 and its corresponding Implementing Regulation (EC) $142 / 201$, it seemed reasonable to test the thermochemical pretreatment (Tch) as one of the methods. Especially that the conditions of the proposed method (similar to the biological pretreatment (BP) defined as temperature phased anaerobic digestion (TPAD) with hyperthermophilic conditions for hydrolysis) are consistent with one of the types of thermal pretreatment which is recommended for sanitising animal by-products from the meat-processing industry (namely processing the material at $70^{\circ} \mathrm{C}$ for at least $60 \mathrm{~min}$.) [2]. The suggested addition of sodium hydroxide also may intensify the process due to fact that sodium at low concentrations is necessary for the methanogenic bacteria, because it plays a significant role during the formation of adenosine triphosphate (ATP) as well as the oxidation of the NADH coenzyme [11, 12]. Moreover, saponification (i.e. reaction between a hydroxide and fats or more precisely triglycerides) results in the formation of long chain fatty acid salts, which may lead to the decrease in the toxicity of these compounds as well as improve the contact between microorganisms and digested materials, thereby enhancing their biodegradability $[13,14]$. Furthermore, thermochemical as well as ultrasonic pretreatments (UD) are indicated as the most effective and economically viable methods [15]. Additionally, in the study kinetic parameters were estimated using the following methods: the transference function, the modified Gompertz model and the logistic function. Additionally, an energy balance evaluation, which is often neglected in literature, was also carried out [15].

\section{Materials and methods}

\subsection{Materials}

The biochemical methane potential (BMP) assays were carried out for two kinds of materials. Sewage sludge (Ss) (a mixture of primary sludge and waste activated sludge) which was collected from a wastewater treatment plant (WWTP) in the Silesia region of Poland. The second material was the co-digestion mixture (CdM) containing (on volatile solids basis): $30 \%$ grease trap sludge and $70 \%$ sewage sludge. Grease trap sludge was obtained from a meat processing plant (the Silesia region of Poland). Characteristics of both substrates as well as the inoculum (from the WWTP) is shown in Table 1.

\subsection{Experimental procedure}

During the experiment the following pretreatment methods were tested: ultrasonic (UD), thermochemical (Tch) and biological pretreatment (BP). The highest dose of sodium was below the inhibition threshold reported by Appels et al. [11], namely 3,500 mg/L. Regardless of the method, the experiment was divided into two stages. In the first phase the 
selection of the most favourable pretreatment conditions took place. Based on the obtained results in the second phase methane potential assays were conducted for the optimal conditions for each type of pretreatment. Selection was made based on the changes of volatile fatty acids (VFAs), total organic carbon (TOC) and chemical oxygen demand (COD) in the supernatant. The BMP assays were carried out using customised equipment consisting of Dreschel bottles, fermentation bottles, an inductive stirring system and biogas collection unit. The batch medium for the BMP assays was prepared according to the procedure described by Owen et al. [16]. The inoculum before introduction to the fermentation bottles was "degassed" by preincubation in an incubator $\left(37^{\circ} \mathrm{C}\right)$ for 5 days. The $\mathrm{pH}$ values of the feedstock in the fermentation bottles were adjusted to $7.0 \mathrm{using}$ $1 \mathrm{M} \mathrm{HCl}$ or $1 \mathrm{M} \mathrm{NaOH}$. Additionally, before closing the fermentation bottles, their headspaces were flushed with nitrogen gas. The bottles were mixed using magnetic stirrers only during gas measurements. Details of the experiment are shown in Fig.1.

Table 1. Characteristics of the batch mixtures used in the study.

\begin{tabular}{|c|c|c|c|c|}
\hline \multirow{2}{*}{ Indicator } & \multirow{2}{*}{ Unit } & \multicolumn{3}{|c|}{ Material } \\
\cline { 3 - 5 } & & Inoculum & $\begin{array}{c}\text { Sewage } \\
\text { sludge }\end{array}$ & $\begin{array}{c}\text { Co-digestion } \\
\text { mixture }\end{array}$ \\
\hline $\mathrm{TS}$ & $\mathrm{g} / \mathrm{L}$ & $15.31-19.51$ & $23.7-24.98$ & $30.32-31.83$ \\
\hline $\mathrm{VS}$ & $\mathrm{g} / \mathrm{L}$ & $9.92-12.4$ & $18.12-18.72$ & $24.78-25.51$ \\
\hline $\mathrm{pH}$ & - & $7.43-7.91$ & $5.73-6.43$ & $5.63-5.83$ \\
\hline $\mathrm{VFAs}$ & $\mathrm{mgCH}_{3} \mathrm{COOH} / \mathrm{L}$ & $674-846$ & $2606-3314$ & $2714-3371$ \\
\hline
\end{tabular}
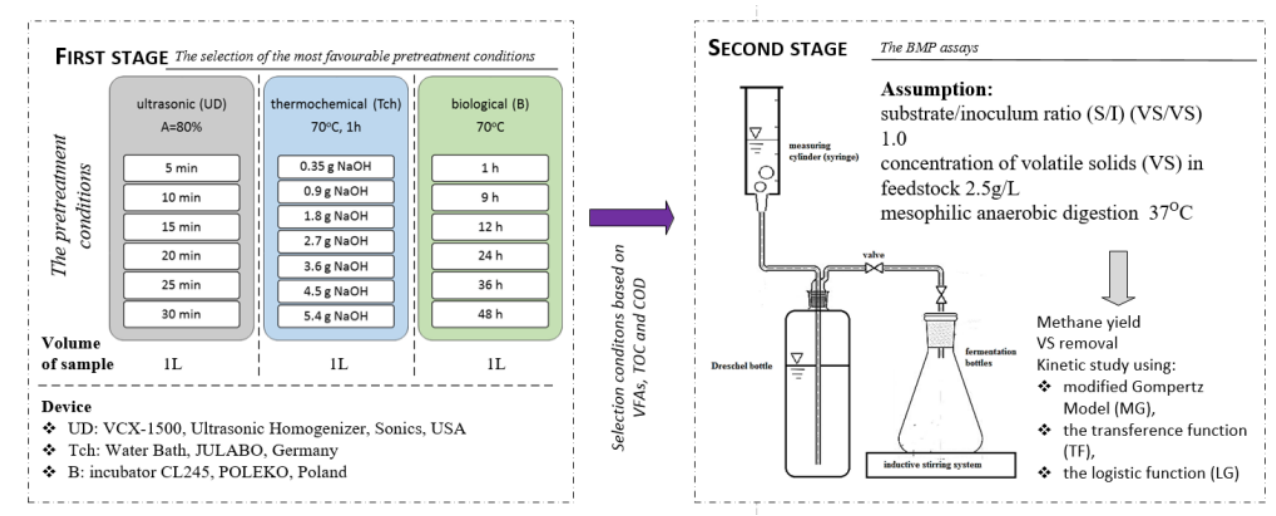

Fig. 1. Scheme of the experiment.

\subsection{Analyses and calculations}

Measurement of $\mathrm{pH}$ values, VFAs, COD and TOC in the supernatant (obtained by centrifugation of the samples at $12100 \mathrm{rcf}$ for 15 minutes using the Eppendorf centrifuge type 5804, followed by filtering through filter papers $(3 \mathrm{w})$ ) as well as total solids (TS) and volatile solids (VS) were determined according to APHA [17]. In turn biogas production was measured using the water displacement method, while the content of methane in the biogas was analysed by a portable gas analyser (NANOSENS DP-27 BIO+, Poland). All obtained gas measurement results were calculated at standard temperature and pressure (STP). Additionally, based on the obtained results, the kinetic parameters were estimated using the three following models: modified Gompertz model, the logistic function and the 
transference function. The equations used in these estimations are presented in study by Li et al. [18]. The estimations of kinetic parameters were made in STATISTICA software using non-linear regression. The above-mentioned software was also used to determine how the tested pretreatment methods affect VFAs, COD and TOC as well as methane yield (one way-ANOVA). In the case of finding statistically significant differences between data a post hoc Tukey honest significance difference (HSD) was carried out. Additionally, the hydrolysis constant rate was estimated using the first-order kinetic model in accordance with the equation presented in [19]. Moreover, for all of the tested pretreatment methods the energy balance was made. Equations and some theoretical assumptions applied for the energy balance came from the work of Dhar et al. [20] and Cho et al. [21].

\section{Results and discussion}

\subsection{Selection of the most favourable pretreatment conditions}

The one-way ANOVA showed significant differences between tested pretreatment methods (see results of the Tukey test in Table 2). Values of COD and TOC for both materials increased gradually with the increase in the sonication time. This is in agreement with the results of many studies reported in the literature $[3,9]$. The highest values of COD (TOC) were observed for the $30 \mathrm{~min}$. exposure, for which, in comparison to the control sample (without conditioning) an increase of up to $157 \%(83 \%)$ and $183 \%(116 \%)$ for Ss and CdM, respectively were recorded. While, for the thermochemical pretreatment, the observed increase of COD (TOC) content was in the range from $111 \%$ to $337 \%$ (from $71 \%$ to 264 ) and $111 \%$ to $601 \%$ (from $53 \%$ to $413 \%$ ) for Ss and CdM, respectively. In turn for BP, the improvement in COD and TOC content were proportional to the incubation time, reaching values of up to $153 \%$ and $93 \%$ for Ss and $163 \%$ and $84 \%$ for CdM. The obtained results (Table 2) also showed that the tested pretreatment methods had the slightest impact on the VFAs concentrations. The longest sonification pretreatment time resulted in a $3 \%$ VFAs increase for both materials, while saponification allowed for an increase of this indicator by $15 \%$ and $8 \%$ for Ss and CdM, respectively. An opposite trend was observed for BP. In the case of this method VFAs concentrations decreased along with the extension of the incubation time.

As shown in Fig. 2 the values of specific energy input (the amount of energy supplied per the initial concentration of total solids in the substrate) for sewage sludge and codigestion mixture ranged from $4,232 \mathrm{~kJ} / \mathrm{kgTS}$ to $18,386 \mathrm{~kJ} / \mathrm{kgTS}$ and from $3,263 \mathrm{~kJ} / \mathrm{kgTS}$ to $15,134 \mathrm{~kJ} / \mathrm{TS}$, respectively. Thus, for almost all of the tested conditions the values were in the typical range reported in the literature, namely from 1,000 to $16,000 \mathrm{~kJ} / \mathrm{kg} \mathrm{TS}$ and depends on the content of total solids in the feedstock [3]. For both materials the total solids content was in the optimal range for sonication (i.e. between from $2.3 \%$ to $3.2 \%$ TS) [22]. 
Table 2. The changes of volatile fatty acids (VFAs), total organic carbon (TOC) and chemical oxygen demand (COD) in the supernatant during the experiment (cases marked with the same letter are not significantly different, $\mathrm{p}>0.05)$.

\begin{tabular}{|c|c|c|c|c|c|c|}
\hline \multirow[b]{2}{*}{ Methods } & \multicolumn{3}{|c|}{ Ss } & \multicolumn{3}{|c|}{ CdM } \\
\hline & $\begin{array}{c}\text { COD } \\
(\mathrm{mg} / \mathrm{L})\end{array}$ & $\begin{array}{c}\text { TOC } \\
(\mathrm{mg} / \mathrm{L})\end{array}$ & $\begin{array}{c}\text { VFAs } \\
(\mathrm{mg} / \mathrm{L})\end{array}$ & $\begin{array}{c}\text { COD } \\
(\mathrm{mg} / \mathrm{L})\end{array}$ & $\begin{array}{c}\text { TOC } \\
(\mathrm{mg} / \mathrm{L})\end{array}$ & $\begin{array}{c}\text { VFAs } \\
(\mathrm{mg} / \mathrm{L})\end{array}$ \\
\hline UD0 & $5918 \pm 207 \mathrm{a}$ & $1870 \pm 9 a$ & $3314 \pm 20 \mathrm{a}$ & $6458 \pm 153 a$ & $1950 \pm 2 \mathrm{a}$ & $3371 \pm 20 \mathrm{ab}$ \\
\hline UD5 & $10050 \pm 348 \mathrm{~b}$ & $2270 \pm 2 b$ & $3343 \pm 75 \mathrm{ab}$ & $11369 \pm 692 b$ & $2510 \pm 9 b$ & $3326 \pm 91 \mathrm{a}$ \\
\hline UD10 & $11575 \pm 246 \mathrm{c}$ & $2700 \pm 15 \mathrm{c}$ & $3343 \pm 17 \mathrm{ab}$ & $12863 \pm 585 \mathrm{c}$ & $3100 \pm 8 \mathrm{c}$ & $3371 \pm 20 \mathrm{ab}$ \\
\hline UD15 & $12763 \pm 390 \mathrm{~cd}$ & $3010 \pm 1 \mathrm{~d}$ & $3349 \pm 49 a b$ & $14031 \pm 303 \mathrm{c}$ & $3360 \pm 2 d$ & $3371 \pm 52 \mathrm{ab}$ \\
\hline UD20 & $13175 \pm 74 d$ & $3100 \pm 5 \mathrm{e}$ & $3371 \pm 71 \mathrm{ab}$ & $15644 \pm 277 \mathrm{~d}$ & $3890 \pm 1 \mathrm{e}$ & $3463 \pm 69 \mathrm{ab}$ \\
\hline UD25 & $14538 \pm 231 \mathrm{e}$ & $3440 \pm 1 \mathrm{f}$ & $3417 \pm 20 \mathrm{ab}$ & $16813 \pm 255 \mathrm{~d}$ & $4440 \pm 2 \mathrm{~g}$ & $3486 \pm 52 b$ \\
\hline UD30 & $15238 \pm 1060 \mathrm{e}$ & $3420 \pm 16 \mathrm{f}$ & $3463 \pm 34 b$ & $18319 \pm 660 \mathrm{e}$ & $4220 \pm 5 \mathrm{f}$ & $3463 \pm 59 \mathrm{ab}$ \\
\hline Tch0 & $4818 \pm 219 a$ & $1500 \pm 23 a$ & $2606 \pm 69 a$ & $5115 \pm 62 \mathrm{a}$ & $1670 \pm 20 \mathrm{a}$ & $2714 \pm 77 \mathrm{a}$ \\
\hline Tch0.35 & $10213 \pm 370 \mathrm{~b}$ & $2570 \pm 93 \mathrm{~b}$ & $2709 \pm 91 \mathrm{a}$ & $10800 \pm 336 \mathrm{~b}$ & $2550 \pm 79 b$ & $2806 \pm 10 \mathrm{~b}$ \\
\hline Tch0.9 & $11525 \pm 98 \mathrm{~b}$ & $2750 \pm 23 b$ & $2857 \pm 20 \mathrm{~b}$ & $13542 \pm 208 \mathrm{c}$ & $3280 \pm 50 \mathrm{c}$ & $2834 \pm 20 \mathrm{bc}$ \\
\hline Tch1.8 & $13475 \pm 337 \mathrm{c}$ & $3700 \pm 93 c$ & $2846 \pm 34 b$ & $19781 \pm 353 d$ & $5000 \pm 89 d$ & $2869 \pm 20 \mathrm{bcd}$ \\
\hline Tch2.7 & $15788 \pm 232 \mathrm{~d}$ & $4230 \pm 62 d$ & $2869 \pm 20 \mathrm{~b}$ & $28981 \pm 865 \mathrm{e}$ & $6880 \pm 105 \mathrm{e}$ & $2874 \pm 10 \mathrm{bcd}$ \\
\hline Tch3.6 & $17538 \pm 509 \mathrm{e}$ & $4540 \pm 80 \mathrm{e}$ & $2949 \pm 34 b c$ & $33213 \pm 477 \mathrm{f}$ & $7660 \pm 80 \mathrm{f}$ & $2909 \pm 10 \mathrm{cde}$ \\
\hline Tch4.5 & $21056 \pm 879 \mathrm{f}$ & $5500 \pm 90 \mathrm{f}$ & $3006 \pm 20 \mathrm{c}$ & $34100 \pm 152 \mathrm{f}$ & $8610 \pm 38 \mathrm{~g}$ & $2943 \pm 10 \mathrm{de}$ \\
\hline Tch5.4 & $21063 \pm 641 \mathrm{f}$ & $5460 \pm 92 \mathrm{f}$ & $3006 \pm 20 c$ & $35900 \pm 1126 \mathrm{~g}$ & $8580 \pm 99 \mathrm{~g}$ & $2989 \pm 10 \mathrm{e}$ \\
\hline BP0 & $4818 \pm 219 a$ & $1500 \pm 2 \mathrm{a}$ & $3314 \pm 20 \mathrm{e}$ & $5115 \pm 62 a$ & $1670 \pm 2 \mathrm{a}$ & $3371 \pm 20 \mathrm{c}$ \\
\hline BP1 & $7406 \pm 198 b$ & $1470 \pm 8 \mathrm{a}$ & $2720 \pm 20 \mathrm{a}$ & $8538 \pm 280 \mathrm{~b}$ & $1750 \pm 2 b$ & $2974 \pm 12 b$ \\
\hline BP9h & $10233 \pm 611 \mathrm{c}$ & $2400 \pm 1 b$ & $2769 \pm 12 \mathrm{ab}$ & $11244 \pm 321 \mathrm{c}$ & $2410 \pm 5 c$ & $2949 \pm 0 b$ \\
\hline BP12h & $10958 \pm 644 \mathrm{~cd}$ & $2510 \pm 2 c$ & $2811 \pm 0 \mathrm{~b}$ & $11650 \pm 402 \mathrm{~cd}$ & $2730 \pm 2 d$ & $2897 \pm 24 a$ \\
\hline BP24h & $11394 \pm 311 \mathrm{de}$ & $2780 \pm 1 \mathrm{~d}$ & $2903 \pm 52 \mathrm{c}$ & $12400 \pm 213 \mathrm{cde}$ & $2840 \pm 0 \mathrm{e}$ & $2949 \pm 0 \mathrm{~b}$ \\
\hline BP36h & $12169 \pm 307 \mathrm{ef}$ & $2890 \pm 30 \mathrm{e}$ & $2957 \pm 12 \mathrm{c}$ & $13050 \pm 1096 \mathrm{de}$ & $3040 \pm 2 \mathrm{f}$ & $2880 \pm 0 \mathrm{a}$ \\
\hline BP48h & $13033 \pm 263 \mathrm{f}$ & $2990 \pm 2 \mathrm{f}$ & $3051 \pm 0 \mathrm{~d}$ & $13488 \pm 734 \mathrm{e}$ & $3080 \pm 7 \mathrm{~g}$ & $2949 \pm 0 b$ \\
\hline
\end{tabular}

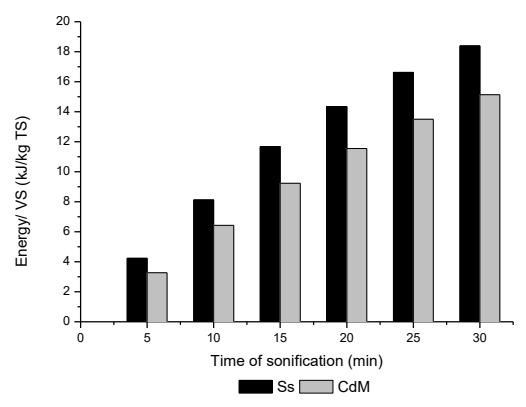

Fig. 2. The specific energy input during sonication of the samples.

The pretreament conditions for the BMP assays were selected based on the results shown in Table 2 as well as the analyses of specific energy inputs. They were as follows: UD 5, 10 , 15 and $20 \mathrm{~min}$. of sonification time; Tch $3.6,4.5$ and $5.4 \mathrm{~g} / \mathrm{L}$ dose of sodium, and for BP 24,36 and $48 \mathrm{~h}$ incubation time at $70^{\circ} \mathrm{C}$. It should be noted that the chosen retention time for $\mathrm{BP}$ is acknowledged in literature as an optimum for the TPAD pretreatment of waste activated sludge [23]. 


\subsection{BMP assays results}

The observed methane yields for Ss as well as for CdM are mostly lower in comparison with the data found in literature. This discrepancy may be explained by the impact of the following factors: the study scale (batch assays, semi-continuous or continuous systems), the origin/source of waste, the content of VS, the characteristics of the inoculum (the origin, activity, concentration), composition of the basic medium, the substrate-inoculum ratio as well as the experiment conditions or lack of results given for standard conditions (STP) $[24,25]$. Despite this, the addition of fat rich material into the feedstock resulted in an increased methane yield of approximately $36 \%$ (from $134.75 \mathrm{~mL} / \mathrm{g}$ VS to $182.84 \mathrm{~mL} / \mathrm{g}$ VS) (Fig. 3.A), which is a result higher than the one reported by Davidsson et al. [26], who noted an increase of the specific methane yield by $9-14 \%$. The one-way ANOVA showed significant differences between the tested pretreatment methods (Fig. $3 \mathrm{~A})$. However, the kind of the used pretreatment method had a significantly bigger effect on the methane yields noted for Ss $(F=16.7, p=0.00)$ than for the CdM (F 3.5, p = 0.07). The highest increase of efficiency of the anaerobic digestion for both materials were obtained for the samples prepared using the thermochemical pretreatment. This action resulted in an increased methane yield of up to $184.28 \mathrm{~mL} / \mathrm{g}$ VS (the sewage sludge pretreated with $4.5 \mathrm{~g} \mathrm{NaOH}$ ) compared to $134.75 \mathrm{~mL} / \mathrm{g}$ VS noted for the control sample. While, thermochemical pretreatment of CdM resulted in an approximately $30 \%$ higher methane yield as compared to the untreated mixture, what is more, this value was $76 \%$ higher than that recorded for anaerobic digestion of sewage sludge without conditioning. Thus, the enhancement of methane production via saponification of the CdM was significantly higher than the results reported in the literature. For instance Carrere et al. [13] reported a very slight impact of this method on the methane potential for batch co-digestion of waste-activated sludge and fatty wastewater (an enhancement ranging from 4 to $7 \%-$ similar to the results obtained in this study for saponification with a $\mathrm{NaOH}$ dose higher than $3.6 \mathrm{~g} / \mathrm{L})$. Also, Battimelli et al. [14] noted a very little increase in the volume of biogas (from 1222 to 1284 and from 1126 to 1166 for aeroflotation fat and carcass fat, respectively). In turn, $\mathrm{Li}$ et al. [27] noted an improved ultimate methane production by $9.9 \pm 1.5 \%$ for a mixture of waste activated sludge and fat, oil grease treated at $\mathrm{pH}=10$ and $55^{\circ} \mathrm{C}$. In turn for UD pretreatment the noted methane yield for the treated materials generally increased with the increase of specific energy input (Fig. 3A). The methane yield was enhanced by $6-21 \%$ for the digester fed with sonified sewage sludge, while, in the literature biogas enhancement ranges from $24 \%$ to $140 \%$ for batch systems, these differences in the efficiency of the UD pretreatment may be linked with sewage sludge characteristics [9]. In comparison to the control sample, methane yield increased by approximately $22 \%$ (from $182.85 \mathrm{~mL} / \mathrm{g}$ VS to $222.41 \mathrm{~mL} / \mathrm{g} \mathrm{VS}$ ). Thus, this study showed an opposite tendency that the ones reported by Li et al. [27] or Luste et al. [28], who noted that ultrasonic pretreatment does not always lead to any significant improvement in the ultimate methane production. Furthermore, sometimes the results obtained for the treated materials are lower in comparison to the digestion without ultrasonic pretreatment. While for BP of Ss, the maximum methane yield was reached for an untreated sample. The opposite trend was observed for CdM. This method allowed for obtaining an approximately $18 \%$ higher methane yield compared to the control sample (untreated CdM). Generally, the use of the selected methods resulted in an increase of volatile solids removal (Fig. 3B). The only exception being the case of the biologically pretreated samples, for which regardless of incubation time, lower volatile solids removal compared to the control sample was observed. 

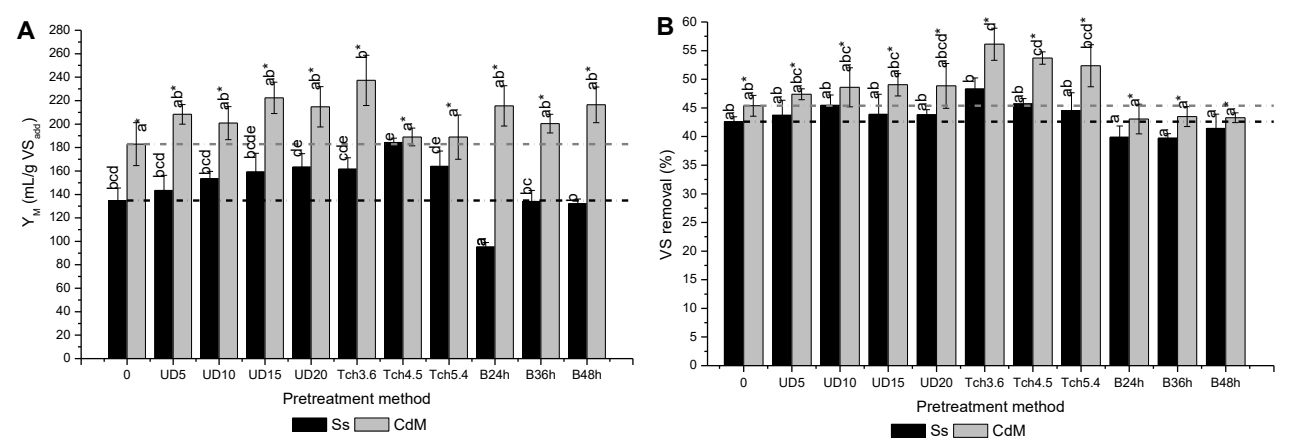

Fig. 3. The methane yield (A) and VS removal (B) of untreated and treated samples (bars marked with the same letter are not significantly different, $p>0.05$; *- Tukey test for CdM).

\subsection{Kinetic study}

The Tch as well as UD considerably enhanced the hydrolysis reaction rate constant. While for BP an opposite trend was observed. In the case of Ss this kinetic parameter increased from 0.17 to 0.38 /day and from 0.17 to 0.29 /day for UD and Tch, respectively. It should be noted that the value for untreated sewage sludge was in the range reported by Zhen et al. [19], Zhang et al. [29] or Vavilin et al. [30]. In turn, for the untreated CdM as compared to the sewage sludge significantly lower hydrolysis reaction rate constant was noted (0.11/day). Tch resulted in approximately $173 \%$ higher value of this parameter as compared to the untreated mixture (from 0.11 day to 0.30 /day), while for UD this kinetic parameter increased up to $209 \%$ (from 0.11 day to $0.34 /$ day). The values of the coefficient of determination were higher than 0.96 indicating that all of the applied kinetic models showed a high degree of fit to the measured data. Moreover, the kinetic analyses showed that generally Tch and UD accelerated the maximum rate of methane production.

\subsection{Energy aspect}

The publications regarding pretreatment methods presented in scientific journals focus primarily on the aspect of anaerobic digestion efficiency enhancement resulting in the increase of methane yield as well as volatile solids removal. While, energy assessments are usually overlooked. This is shortsighted when taking into account that not all of the proposed pretreatment methods in scientific reports have an energy self-sufficiency, meaning that the potential gains do not offset the energy requirements of these methods.

In this study, the net energy production (defined as the difference between the output and input energy) was evaluated. As shown in Fig.4 the calculated net energy production showed that for Tch as well as UD the energy gain not only covers the requirements of the method itself but also allows for a significant improvement of the WWTPs profitability.

While, in the case of BP, the energy analyses showed that it is not economically viable due to energy consumption exceeding the energy obtained from the methane production (as shown in Fig. 4). These observations are similar to results noted by Dhar et al. [20], who reported that for anaerobic digestion of municipal waste activated sludge, ultrasound (1000 $\mathrm{kJ} / \mathrm{kg}$ total suspended solids) and thermal pretreatments $\left(50-90^{\circ} \mathrm{C}\right)$ are economically justified, since they allow to reduce operating costs by $\$ 44-66 /$ ton dry solids in comparison to conventional anaerobic digestion without pretreatments. Also, Cano et al. [15] noted that thermal pretreatments have an energy self-sufficiency to be implemented in a wastewater treatment plant. 
The values for UD as well as Tch shown in Fig. 4. are much lower than the ones reported in literature. For instance, Serrano et al. [31] obtained a net energy production of $1963 \mathrm{~J} / \mathrm{gVS}$ for co-digestion of pre-treated sewage sludge and strawberry extrudate. In turn, Cho et al. [21] reported a positive net energy production of $6300 \mathrm{~J} / \mathrm{g}$ VS for anaerobic digestion of mixed-microalgal biomass after alkali pretreatment.

Moreover, the energy consumption during UD as well as Tch pretreatments were lower than the limit suggested by Cano et al. [15] (energy requirements should be below $\left.0.2 \mathrm{kWh} / \mathrm{m}^{3}\right)$.

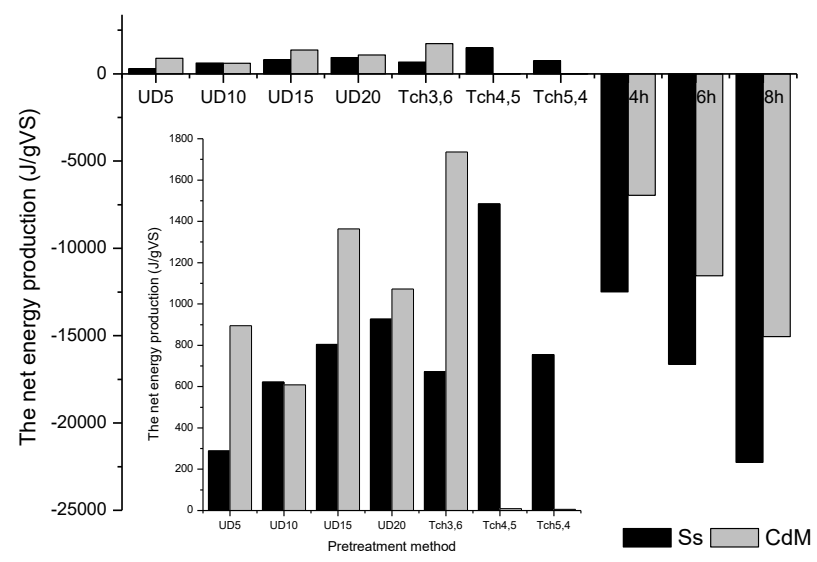

Fig. 4. The net energy production for pretreatment methods tested in this study.

\section{Conclusion}

The experimental results showed that both UD and TCh can improve the solubilisation of organic matter measured as the change of COD and TOC content positively affecting the methane yield. While BP only enhanced the methane production for CdM in comparison to the untreated sample. In terms of methane yield the experimental results showed the most promising approach seems to be the co-digestion of a Tch pretreated feed. The energy balance showed that only UD and Tch are energy self-sufficient.

\section{Acknowledgements}

The study was supported by the BS/PB-401-301/13.

\section{References}

1. V.K. Tyagi, S.L Lo, Renew. Sust. Energ. Rev. 25 708-728 (2013)

2. J. Grim, P. Malmros, A. Schnürer, Å. Nordberg, Energy 79 419-427 (2015)

3. H. Carrere, G. Antonopoulou, R. Affes, F. Passos, A. Battimelli, G. Lyberatos, G.I. Ferrer, Bioresour. Technol. 199 386-397(2016)

4. P. Neumann, S. Pesante, M. Venegas, G. Vidal, Rev. Environ. Sci. Biotechnol. 15, 2, 173-211 (2016)

5. A. Grosser, E. Neczaj, Energ. Convers Manage. 125, 301-308 (2016)

6. J. Mata-Alvarez, J. Dosta, M.S. Romero-Güiza, X. Fonoll, M. Peces, S. Astals, Renew. Sust. Energ. Rev. 36, 412-427 (2014) 
7. F.A. Shah, Q. Mahmood, N. Rashid, A. Pervez, I.A. Raja, M.M. Shah, Renew. Sust. Energ. Rev. 42, 627-642 (2015)

8. J. Ariunbaatar, A. Panico, G. Esposito, F. Pirozzi, P.N. Lens, Appl. Energy 123, 143-156 (2014)

9. S. Pilli, P. Bhunia, S. Yan, R.J. LeBlanc, R.D. Tyagi, R. Y. Surampalli, Ultrason. Sonochem. 18, 1, 1-18. (2011)

10. M.M. Alves, M.A. Pereira, D.Z. Sousa, A.J. Cavaleiro, M. Picavet, H. Smidt, A.J. Stams, Microbial. Biotechnology 2, 5, 538-550 (2009)

11. Y. Chen, J.J. Cheng, K.S. Creamer, Bioresour. Technol. 99, 4044-64 (2008)

12. L. Appels, J. Baeyens, J. Degrève, R. Dewil, Prog. Energ. Combust 34, 6, 755-781 (2008)

13. H. Carrere, Y. Rafrafi, A. Battimelli, M. Torrijos, J.P. Delgenes, C. Motte, Chem. Eng. J. 210, 404-409 (2012)

14. A. Battimelli, H. Carrère, J.P. Delgenès, J. P. Bioresour. Technol. 100, 15, 3695-3700 (2009)

15. R. Cano, S.I. Pérez-Elvira, F. Fdz-Polanco, Appl. Energy 149, 176-185 (2015)

16. W.F. Owen, D.C. Stuckey, J.B. Healy, L.Y. Young, P.L. McCarty, Water Res. 13, 6, 485-492 (1979)

17. APHA. Standard methods for the examination of water and wastewater (American Public Health Association, Washington. DC, 1999)

18. L. Li, X. Kong, F. Yang, D. Li, Z. Yuan, Y. Sun, Appl. Biochem. Biotechnol. 166, 5, 1183-1191 (2012)

19. G. Zhen, X. Lu, T. Kobayashi, Y.Y. Li, K. Xu, Y. Zhao, Appl. Energy 148, 78-86 (2015)

20. B.R. Dhar, G. Nakhla, M.B. Ray, Waste Manage. 32, 3, 542-549 (2012)

21. S. Cho, S. Park, J. Seon, J. Yu, T. Lee, Bioresour. Technol. 143, 330-336 (2013)

22. K.-Y. Show, T. Mao, D.-J. Lee, Water Res. 41, 20, 4741-4747 (2007)

23. H. Ge, P.D. Jensen, D.J. Batstone, Water Res. 45, 1597-1606 (2011)

24. F. Raposo, M.A. De la Rubia, V. Fernández-Cegrí, R. Borja, Renew. Sust. Energ. Rev. 16, 1, 861-877 (2012)

25. L. Angelidaki, M. Alves, D. Bolzonella, L. Borzacconi, J.L. Campos, A.J. Guwy, J.B. Van Lier, Water Sci. Technol. 59, 5, 927-934 (2009)

26. A. Davidsson, C. Lövstedt, J. La Cour Janse, C. Gruvberger, H. Asperge, Waste Manage. 28, 6, 986-992 (2008)

27. C. Li, P. Champagne, B.C. Anderson, Bioresour. Technol. 130, 187-197 (2013)

28. S. Luste, S. Luostarinen, M. Sillanpää, J. Hazard Mater. 164, 1, 247-255 (2009)

29. P. Zhang, C.J. Lin, J. Liu, P. Pongprueksa, S.A. Evers, P. Hart, Renewable Energy 68, 304-313 (2014)

30. V.A. Vavilin, B. Fernandez, J. Palatsi, X. Flotats, Waste Manage. 28, 6, 939-951 (2008)

31. A. Serrano, J.A. Siles, M. C. Gutiérrez, M.Á. Martín, 90, 25-33 (2015) 